\title{
Development of terbinafine solid lipid nanoparticles as a topical delivery system
}

This article was published in the following Dove Press journal:

International Journal of Nanomedicine

14 August 2012

Number of times this article has been viewed

\author{
Ying-Chen Chen ${ }^{\text {* }}$ \\ Der-Zen $\mathrm{Liu}^{2 *}$ \\ Jun-Jen Liu ${ }^{3}$ \\ Tsung-Wei Chang' \\ Hsiu-O Ho' \\ Ming-Thau Sheu ${ }^{1,4}$ \\ 'School of Pharmacy, College of \\ Pharmacy, ${ }^{2}$ Graduate Institute of \\ Biomedical Materials and Engineering, \\ ${ }^{3}$ School of Medical Laboratory \\ Science and Biotechnology, ${ }^{4}$ Clinical \\ Research Center and Traditional \\ Herbal Medicine Research Center, \\ Taipei Medical University Hospital, \\ Taipei, Taiwan \\ *Ying-Chen Chen and Der-Zen Liu \\ contributed equally in the preparation \\ of this manuscript.
}

Abstract: To resolve problems of long treatment durations and frequent administration of the antifungal agent terbinafine (TB), solid lipid nanoparticles (SLNs) with the ability to load lipophilic drugs and nanosize were developed. The SLNs were manufactured by a microemulsion technique in which glyceryl monostearate (GMS), glyceryl behenate $\left(\right.$ Compritol $^{\circledR} 888$; Gattefossé), and glyceryl palmitostearate (Precirol ${ }^{\circledR}$ ATO 5; Gattefossé) were used as the solid lipid phases, Tween ${ }^{\circledR}$ and Cremophor ${ }^{\circledR}$ series as the surfactants, and propylene glycol as the cosurfactant to construct ternary phase diagrams. The skin of nude mice was used as a barrier membrane, and penetration levels of TB of the designed formulations and a commercial product, Lamisil $^{\circledR}$ Once $^{\mathrm{TM}}$ (Novartis Pharmaceuticals), in the stratum corneum (SC), viable epidermis, and dermis were measured; particle sizes were determined as an indicator of stability. The optimal SLN system contained a $<5 \%$ lipid phase and $>50 \%$ water phase. The addition of ethanol or etchants had no significant effect on enhancing the amount of TB that penetrated the skin layers, but it was enhanced by increasing the percentage of the lipid phase. Furthermore, the combination of GMS and Compritol ${ }^{\circledR} 888$ was able to increase the stable amount of TB that penetrated all skin layers. For the ACP1-GM1 (4\% lipid phase; Compritol ${ }^{\circledR}$ 888: GMS of 1:1) formulation, the amount of TB that penetrated the SC was similar to that of Lamisil ${ }^{\circledR}$ Once $^{\mathrm{TM}}$, whereas the amount of TB of the dermis was higher than that of Lamisil ${ }^{\circledR}$ Once $^{\mathrm{TM}}$ at 12 hours, and it was almost the same as that of Lamisil ${ }^{\circledR}$ Once $^{\mathrm{TM}}$ at 24 hours. It was concluded that the application of ACP1-GM1 for 12 hours might have an efficacy comparable to that of Lamisil ${ }^{\mathbb{R}}$ Once $^{\mathrm{TM}}$ for 24 hours, which would resolve the practical problem of the longer administration period that is necessary for Lamisil ${ }^{\circledR}$ Once $^{\mathrm{TM}}$.

Keywords: terbinafine, solid lipid nanoparticle, topical delivery system

\section{Introduction}

With approximately $40 \%$ of candidate products now under clinical evaluation, topical therapy is considered the most innovative research area in drug delivery. It offers the following advantages over the oral route: (1) avoidance of hepatic first-pass metabolism, (2) self-administration with ease, convenience, and generally good acceptance by patients, (3) the ability to control drug delivery for a longer time than the usual gastrointestinal transit of oral dosage forms, and (4) fewer safety concerns because serum absorption tends to be minimal. ${ }^{1,2}$

Tinea pedis, usually called "athlete's foot," is a common skin disease of the interdigital toe spaces. Up to $15 \%$ of the population may have this disease, which is usually caused by dermatophyte fungi, ${ }^{3}$ and is often treated with antifungal agents. Terbinafine (TB), a synthetic allylamine, exerts potent broad-spectrum fungicidal activity by
Correspondence: Ming-Thau Sheu; Hsiu-O Ho $250 \mathrm{Wu}$-Hsing Street, Taipei I I0, Taiwan

Tel +88622377 1942

Fax +866223771942

Email mingsheu@tmu.edu.tw; hsiuoho@tmu.edu.tw 
inhibiting squalene epoxidase. TB is administered orally and topically, and both are generally well tolerated; however, about $40 \%$ of the dose undergoes first-pass metabolism and is bound extensively to plasma proteins via oral administration. ${ }^{4}$ In fact, the required concentration for antimycotic activity at the target skin site may be more easily achieved after topical dosing, if good drug release and penetration are ensured. To attain similar local drug concentrations, a higher oral dose generally needs to be administered, which increases the risk of adverse effects. Usually, topical administration results in much lower, often undetectable systemic levels, thus reducing the possible toxicity of the drug. ${ }^{5}$ Various topical forms of TB marketed under the trademark Lamisil ${ }^{\circledR}$ (Novartis Pharmaceuticals, East Hanover, NJ), such as cream, gel, spray solution, and film-forming solution (FFS; eg, Lamisil ${ }^{\circledR}$ Once ${ }^{\mathrm{TM}}$; Novartis Pharmaceuticals), were approved for treating tinea pedis in many countries. ${ }^{6}$ In vitro TB is the most active against dermatophytes, such as Trichophyton, Microsporum, and Epidermophyton spp., with minimum inhibitory concentrations (MICs) of $0.001-0.05 \mu \mathrm{g} / \mathrm{mL}$. That of azole antifungal agents (eg, clotrimazole, miconazole, bifonazole, or oxiconazole), on the other hand, range from 0.1 to $>10 \mu \mathrm{g} / \mathrm{mL} .^{7,8}$ Moreover, the TB treatment duration is shorter in most cases. ${ }^{9,10}$ Based on several clinical studies conducted in humans ${ }^{11-13}$ and animals, ${ }^{14,15}$ it was noted that TB accumulates in the skin and persists at high concentrations for up to several weeks after discontinuing drug application. The superior efficacy of TB after the end of the treatment period is attributed to its fungicidal effect in addition to the favorable pharmacokinetic characteristics of substantial and rapid penetration into the stratum corneum (SC), where it remains in the skin for a long time after discontinuing treatment. This effect is particularly evident in the new TB formulation, Lamisil ${ }^{\circledR}$ Once $^{\mathrm{TM}}$, for which long-term cure rates continue to increase after a single application. This became a reality using an FFS containing $1 \% \mathrm{~TB}$, a bioadhesive acrylate/acrylamide copolymer, hydroxypropylcellulose, medium chain triglycerides, and ethanol. Ethanol rapidly evaporates after application of this FFS on the skin, resulting in a high concentration of TB. This concentration gradient promotes penetration of TB into the skin, which is further facilitated by the alcohol.,16 Moreover, the adhesive polymer matrix inhibits the easy removal of TB from the skin surface and thus maintains an ongoing absorption process for an additional few days. ${ }^{17}$

Solid lipid nanoparticles (SLNs) are comprised of mainly physiological lipids that are in the solid phase at room temperature and surfactants for emulsification; mean diameters range from $50-1000 \mathrm{~nm} .{ }^{18,19}$ SLNs were developed as an alternative delivery system because of their several advantages, such as the feasibility of incorporating lipophilic and hydrophilic drugs, negligible skin irritation, improved physical stability, and lower costs compared to liposomes. ${ }^{20}$ Moreover, SLNs have distinct occlusive properties due to the formation of an intact film on the skin surface upon drying, which prohibits transepidermal water loss and favors the drug penetrating through the SC and epidermal targeting. ${ }^{21,22}$ In addition to the nonspecific occlusion effect, enhanced drug penetration might be related to the nanometer-sized SLNs because the highly specific surface area facilitates contact of the encapsulated drug with the SC and may favor accumulation for several hours, which allows for sustained drug release..$^{23,24}$ SLNs are used to improve the skin uptake of several drugs. The cumulative amount of penciclovir that penetrated through excised rat skin from SLNs prepared by a double (w/o/w) emulsion technique was more than twice that of a commercial cream at 12 hours after administration. The interaction between SLNs and the skin changed the morphology of the SC and broke down the close conjugation of the corneocyte layers, which resulted in increased permeation of penciclovir in the skin dermis. ${ }^{23}$ Mandawgade et $\mathrm{al}^{25}$ found that less skin irritation, greater occlusivity, and slow drug release were observed with tretinoin-loaded SLN-based topical gels compared to a commercial product, and the SLNs were produced by a microemulsion technique using natural solid lipids (stearine fractions). A novel SLN formulation loaded with all-trans retinoic acid (RA), a lipid acid, and a lipophilic amine was designed, which did not require the application of organic solvents; it thus became possible to obtain high loading capacities (almost 100\%) for RA. Furthermore, it was stable for at least 360 days at room temperature, and there was reduced RA-induced skin irritation compared to the marketed conventional RA cream. ${ }^{26}$

The dermal location of SLNs should be such that they interfere with the establishment of fungal infection. This provides primary fungicidal activity against dermatophytes as well as a long-term effect of TB as a reservoir even after cessation of application to prevent recurrence. Hence, exploring the potential of SLNs to improve the topical delivery of TB seems worthwhile. The present work focused on the preparation, characterization, in vitro transdermal permeation, and skin targeting behaviors of TB-loaded SLNs.

\section{Materials and methods Materials}

Cremophor $^{\circledR}$ EL, RH40, and RH60 were supplied by BASF (Ludwigshafen, Germany). Gelucire ${ }^{\circledR}$ 39/01, Gelucire ${ }^{\circledR}$ 
44/14, glyceryl behenate (Compritol ${ }^{\circledR} 888$ ), and glyceryl palmitostearate $\left(\right.$ Precirol $^{\circledR}$ ATO 5; ATO 5) were offered by Gattefossé (Saint-Priest, France). Polysorbate (Tween ${ }^{\circledR}$ ) 80, 60, 40, and 20, and 1,2-propylenglycol (PG) were provided by Riedel-de Haën (Seelze, Germany). Glyceryl monostearate (GMS) was from Sasol (Johannesburg, South Africa). Terbinafine $\mathrm{HCl}$ (TB) was provided by Farvatis Pharma and Chemicals (New Castle, DE). All other chemicals used were of reagent or pharmaceutical grade.

\section{Analysis of TB concentrations}

TB was analyzed by high-performance liquid chromatography (HPLC; Pump PU-980; Jasco, Tokyo, Japan) with a UV detector (UV-975; Jasco). The concentration of TB was determined using a Synergi ${ }^{\mathrm{TM}}$ Fusion-RP 80 column $(4 \mu \mathrm{m}$, $150 \times 4.6 \mathrm{~mm})$. The mobile phase used acetonitrile $/ \mathrm{H}_{2} \mathrm{O}(65 / 35$, $\mathrm{v} / \mathrm{v})$, consisting of $5 \mathrm{mM}$ ammonium acetate and $0.5 \%(\mathrm{v} / \mathrm{v})$ formic acid at a flow rate of $1.2 \mathrm{~mL} / \mathrm{min}$. The column effluent was monitored by an ultraviolet detector at a wavelength of $246 \mathrm{~nm}$. The HPLC method was validated to have an acceptable coefficient of variation for accuracy and precision.

\section{Solubility test of TB in lipids}

Lipids ( $5 \mathrm{~g}$ ) were prepared at a temperature above the melting point of the lipid, and an excess amount of TB was added to each screw-capped test tube. After sealing, the tubes were vigorously vortexed and shaken in an isothermal shaker for 24 hours. After reaching equilibrium, each tube was centrifuged, and the clear supernatant layer was suitably diluted and analyzed by HPLC as described above to determine the solubility of TB in various lipids.

\section{Ternary phase diagram of SLNs}

Ternary phase diagrams of oil, surfactant, and cosurfactant were developed using a water titration method. First, the surfactant and cosurfactant were mixed in weight ratios of $4: 1,1: 1$, and $1: 4$ to form surfactant/cosurfactant mixtures. Then, the lipid was added, warmed to a temperature above the melting point of the lipid, and gently mixed to form a monophasic mixture. Ternary phase diagrams forming the SLNs were constructed with respect to the lipid and surfactant/ co-surfactant mixture at weight ratios of 1:9-9:1 by visually observing the phase clarity to identify the transparency, viscosity, and uniformity after slow titration with aliquots of distilled water. These were allowed to sit at room temperature to attain equilibrium. After equilibrium was reached, the mixtures were further titrated with water until they became turbid. Clear and isotropic samples were deemed within the
SLN region. Based on the results, appropriate percentages of lipid, surfactant, and cosurfactant were selected from the phase diagram and used to prepare the SLNs.

\section{Preparation of the SLNs}

To form SLNs by the microemulsion method, the microemulsion must be produced at a temperature above the melting point of the lipid. The commercial product, Lamisil ${ }^{\circledR}$ Once $^{\mathrm{TM}}$, contains 1\% terbinafine (molecular weight [MW]: 291.43). Terbinafine $\mathrm{HCl}$ (MW: 327.93 ) was used in the study, and the ratio of terbinafine $\mathrm{HCl}$ is $1.13 \%$, so there was $1 \%$ terbinafine in each SLN formulations, which is the same as Lamisil ${ }^{\mathbb{8}}$ Once $^{\mathrm{TM}}$. First, TB was mixed with the lipid, and the prepared surfactant/cosurfactant mixture was then added and warmed to a temperature above the melting point of the lipid to cause the lipid to liquefy. Water was heated to the same temperature as the lipid phase and then slowly poured in, stirring gently. Transparent, thermodynamically stable SLNs were formed when the compounds were mixed in the appropriate ratio for microemulsion formations (ie, oil:surfactant/cosurfactant mixture:water of 3:37:60) at room temperature.

\section{In vitro transdermal penetration}

In vitro permeation of SLN formulations was evaluated using hairless skin samples excised from nude mice (National Laboratory Animal Center, Taipei, Taiwan). Skin samples including the SC, viable epidermis (VE), and dermis from the abdomen and back were taken from the nude mice at thicknesses of $0.55-1.20 \mathrm{~mm}$. The skin was used as a barrier membrane in a Franz cell to study the transdermal penetration of TB. The volume of the Franz cell receiver compartment was $6.4 \mathrm{~mL}$, and the contact area between the donor and receiver compartments was $2.835 \mathrm{~cm}^{2}$. Either SLN formulations or Lamisil ${ }^{\circledR}$ Once ${ }^{\mathrm{TM}}(0.165 \mathrm{~g})$ was applied to the donor compartment. One hour after application, parafilm was used to seal the top of the donor cell to form a closed administration system. Phosphate-buffered saline (PBS; $6.4 \mathrm{~mL}$; pH 7.4, containing $8 \mathrm{mM} \mathrm{Na}_{2} \mathrm{HPO}_{4}, 22 \mathrm{mM} \mathrm{NaH}_{2} \mathrm{PO}_{4}$, and $150 \mathrm{mM}$ $\mathrm{NaCl}$ ) was added to the receiver compartment, which was then stirred at $400 \mathrm{rpm}$ with a magnetic stirring bar and maintained at $37.0^{\circ} \mathrm{C} \pm 0.5^{\circ} \mathrm{C}$. Samples $(200 \mu \mathrm{L})$ were taken at $1,3,6,12,24$, and 48 hours. Additional $(200 \mu \mathrm{L})$ fresh PBS was added to replenish the compartment after each sampling. Samples were subjected to an HPLC analysis as described in the above section, Analysis of TB concentrations.

After the penetration study, the skin sample was retrieved from the Franz cell, and excessive SLN formulation was washed off with PBS. The SC was removed by tape stripping, 
and the VE and dermis were divided using a dull scalpel blade, which were then lyophilized. The dried and weighed $\mathrm{SC}, \mathrm{VE}$, and dermis were put into $10 \mathrm{~mL}$ of extraction solution (methanol:0.72 $\mathrm{M}$ triethylamine aqueous solution of $8: 2)^{5,16}$ and vortexed for 24 hours at $37^{\circ} \mathrm{C}$. The supernatant was analyzed to determine the concentrations of TB in different skin layers. The TB content was normalized to the weights of the SC, VE, and dermis.

\section{Analysis of particle size}

On days $1,2,3,4,5,6,7,14,28$, and 56 after preparation of the SLNs, 100-200 $\mu \mathrm{L}$ of a sample was diluted with deionized water, and the particle size was determined in triplicate by an N5 submicron particle-size analyzer (Beckman Coulter, Miami, FL).

\section{Statistical analysis}

All results are presented as the mean \pm standard deviation (SD) of at least triplicate determinations. The significance between means was analyzed by Student's $t$-test (PASW Statistics 18.0, Chicago, IL), and $P<0.05$ was considered statistically significant.

\section{Results and discussion Solubility test of TB in lipids}

The solubility of TB was found to be $69.8 \pm 0.5 \mathrm{mg} / \mathrm{g}$ in GMS at $70^{\circ} \mathrm{C}, 41.0 \pm 0.3 \mathrm{mg} / \mathrm{g}$ in $\mathrm{Compritol}^{\circledR} 888$ at $90^{\circ} \mathrm{C}$,
$27.2 \pm 0.6 \mathrm{mg} / \mathrm{g}$ in Precirol ${ }^{\circledR}$ ATO 5 at $65^{\circ} \mathrm{C}, 5.4 \pm 0.1 \mathrm{mg} / \mathrm{g}$ in Gelucire ${ }^{\circledR} 39 / 01$ at $50^{\circ} \mathrm{C}$. TB was insoluble in Gelucire ${ }^{\circledR}$ $44 / 14$ at $60^{\circ} \mathrm{C}$. One of the most important factors determining the loading capacity of SLNs is the solubility of the drug in the melted lipid. Typically, the solubility should be higher than required because it decreases when the mixture is cooled down and might even be lower in the solid lipid. ${ }^{2}$ Hence, because TB achieves good solubility in them, we selected GMS, Compritol ${ }^{\circledR} 888$, and Precirol ${ }^{\circledR}$ ATO 5 as the lipid phases with the surfactant/cosurfactant mixture and water to set up ternary phase diagrams of the SLNs.

\section{Ternary phase diagram of the SLNs}

A representative ternary phase diagram marked with a gray region indicating the microemulsion formation is shown in Figure 1, and SLNs were formed with $<5 \%$ lipid phase and $>50 \%$ water. Hence, the ratio of lipid phase:surfactant/ cosurfactant mixture:water phase used in this study was 3:37:60 because SLNs still formed even with minor deviations of these amounts used. Clear and stable formulations of GMSa, CPa, ATOa, ATOb, and ATOc were modified for further studies (Table 1).

\section{Analysis of particle size}

The particle sizes of all formulations examined changed with respect to time, as demonstrated in Figure 2. Particle sizes of most of the SLN formulations ranged from 80-200 nm soon

\section{Ternary phase diagram (SLN)}

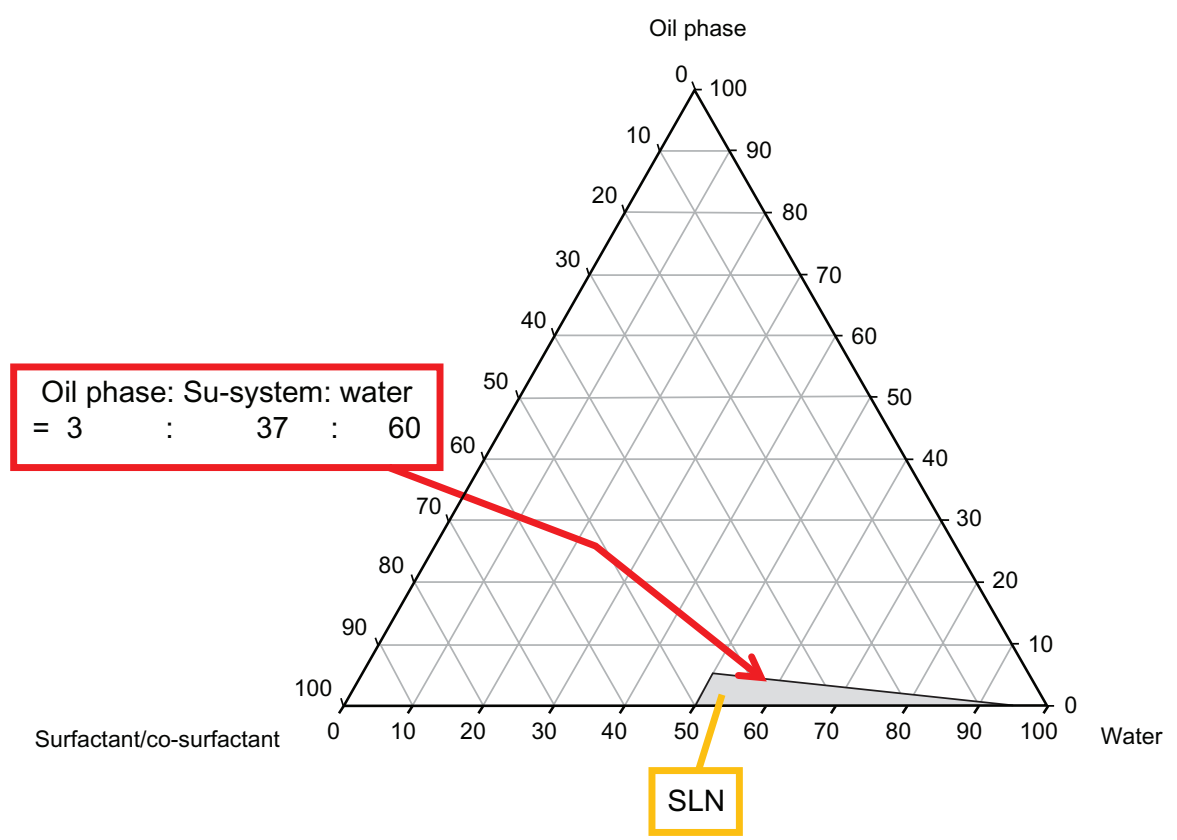

Figure I A representative ternary phase diagram of the microemulsion system that is capable of forming solid lipid nanoparticles (SLNs). 
Table I Components of various solid lipid nanoparticle (SLN) formulations examined in this study

\begin{tabular}{|c|c|c|c|}
\hline $\mathbf{R x}$ & Oil phase & Surfactant:cosurfactant (ratio) & Oil:surfactant/cosurfactant:water (ratio) \\
\hline GMSa & GMS & RH40:PG (4:I) & $3: 37: 60$ \\
\hline $\mathrm{CPa}$ & $\mathrm{CP}$ & RH40:PG (4:I) & $3: 37: 60$ \\
\hline ATOa & Precirol $^{\circledR}$ ATO 5 & RH40:PG (I:I) & $3: 37: 60$ \\
\hline ATOb & Precirol $^{\circledR}$ ATO 5 & Tween ${ }^{\circledR}$ 40:PG (I:I) & $3: 37: 60$ \\
\hline ATOc & Precirol $^{\circledR}$ ATO 5 & RH40:PG (4:I) & $3: 37: 60$ \\
\hline $\mathrm{CPal}$ & $\mathrm{CP}$ & RH40:PG (4:I) & 3:37:60 (5\% ethanol) \\
\hline $\mathrm{CPbIO}$ & $\mathrm{CP}$ & RH40:PG (4:I) & 3:37:60 ( $10 \%$ citric acid $)$ \\
\hline $\mathrm{CPclO}$ & $\mathrm{CP}$ & RH40:PG (4:I) & $3: 37: 60(10 \%$ tartaric acid $)$ \\
\hline $\mathrm{CPbl}$ & $\mathrm{CP}$ & RH40:PG (4:I) & 3:37:60 ( $1 \%$ citric acid $)$ \\
\hline $\mathrm{CPbI} *$ & $\mathrm{CP}$ & RH40:PG (4:I) & 3:37:60 (I\% citric acid) after \\
\hline CPA & $\mathrm{CP}$ & RH40:PG (4:I) & $4: 37: 59$ \\
\hline CPB & $\mathrm{CP}$ & RH40:PG (4:I) & $5: 37: 58$ \\
\hline СРC & $\mathrm{CP}$ & RH40:PG (4:I) & $6: 37: 57$ \\
\hline CPI-GMI & CP:GMS (I:I) & RH40:PG (4:I) & 3:37:60 \\
\hline ACPI-GMI & CP:GMS (I:I) & RH40:PG (4:I) & $4: 37: 59$ \\
\hline ACP3-GMI & CP:GMS (3:I) & RH40:PG (4:I) & 4:37:59 \\
\hline BCPI-GMI & CP:GMS (I:I) & RH40:PG (4:I) & $5: 37: 58$ \\
\hline
\end{tabular}

Abbreviations: GMS, glyceryl monostearate; CP, Compritol ${ }^{\circledR} 888$; RH40, Cremophor RH40; PG, I,2-propylene glycol.

after SLN preparation, except for CPC at $1019.5 \pm 115.7 \mathrm{~nm}$. This seemed to be because the ratio of the lipid phase was $>5 \%$. Formulation GMSa had a particle size of $52.6 \pm 0.8 \mathrm{~nm}$, but it had increased to larger than $3000 \mathrm{~nm}$ after 1 day, and this was also observed for those formulations containing a larger fraction of GMS, eg, ACP1-GM3. On day 28, the particle sizes of formulations $\mathrm{CPa}$ and ATOb were $243.3 \pm 57.8$ and $197.6 \pm 10.6 \mathrm{~nm}$, respectively, whereas those of other formulations were $>3000 \mathrm{~nm}$. However, on day 56, ATOb was $604.7 \pm 38.9 \mathrm{~nm}$. Although ACP1-GM1 had similar or better penetration amounts of TB in each skin layer than Lamisil $^{\circledR}$ Once ${ }^{\mathrm{TM}}$, it remained stable for only 7 days.

\section{The number of tape strippings}

Since the number of tape strippings to remove SC differed among previous studies, the surface morphology of SC

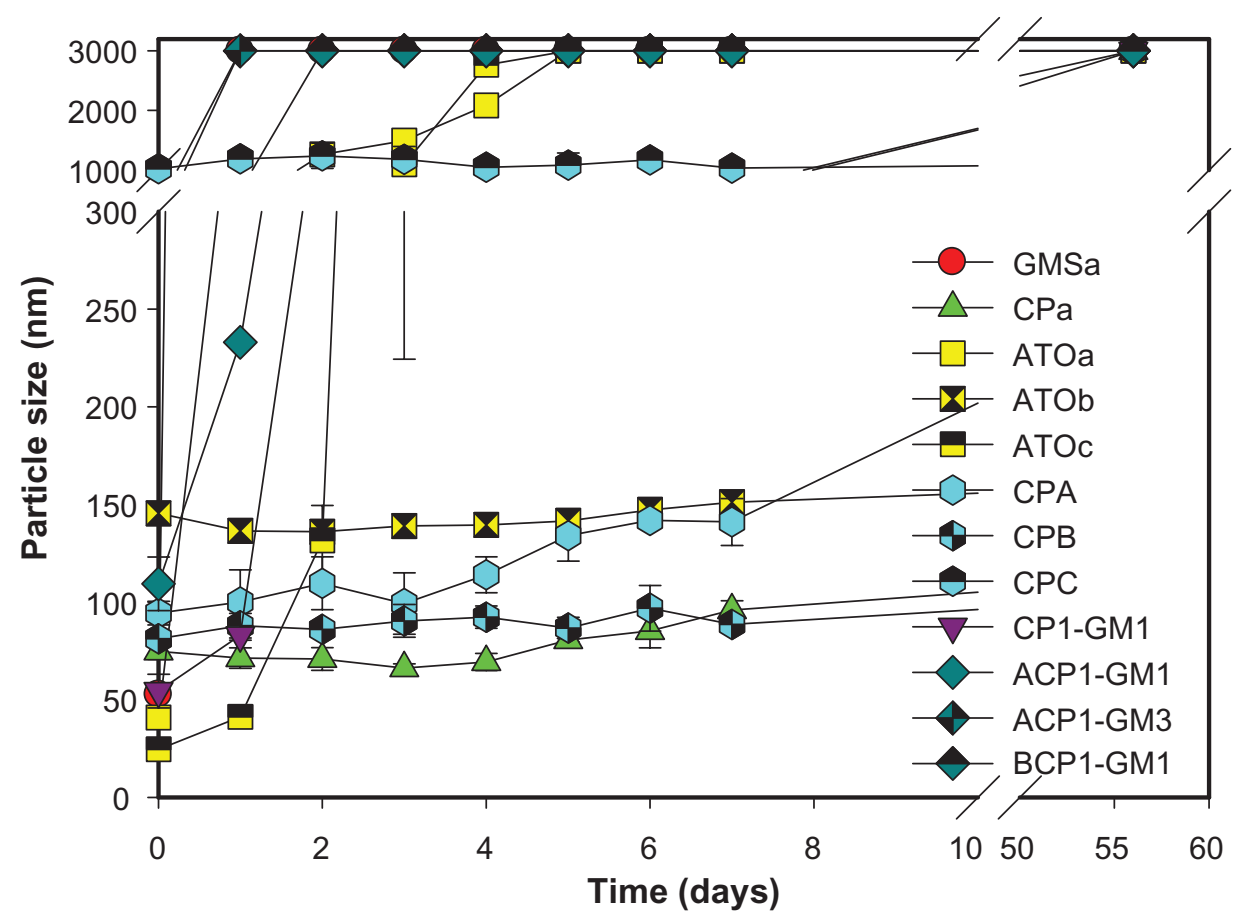

Figure 2 Changes of particle sizes for various solid lipid nanoparticle (SLN) formulations at different time points. Abbreviations: GMS, glyceryl monostearate; CP, Compritol ${ }^{\circledR}$ 888; RH40, Cremophor RH40; PG, I,2-propylene glycol. 
without and after 1, 5, 10, 15, and 20 times of tape stripping after in vitro transdermal penetration was observed in scanning electron microscopy images (Figure 3) to obtain the appropriate number of tape strippings. The tight structure of SC was seen without tape stripping, and it persisted after tape stripping 1, 5, and 10 times. SC did not appear until after tape stripping 15 times, but SC and VE were eliminated after 20 times. Similar SEM images were also revealed without in vitro transdermal penetration (data not shown). Therefore, $\mathrm{SC}$ of nude mice was completely removed by tape stripping 15 times, which was also shown in Sachdeva et $\mathrm{al}^{27}$ in the measurement of transepidermal water loss.

\section{In vitro transdermal penetration}

The transdermal penetration of the commercial product Lamisil $^{\circledR}$ Once ${ }^{\mathrm{TM}}$ was evaluated, and concentrations of TB in different skin layers were analyzed after administration for 1 , $3,6,12$, and 24 hours, as shown in Figure 4. Concentrations reached $30.3 \pm 1.2 \mu \mathrm{g} / \mu \mathrm{g}$ in the $\mathrm{SC}$ at 3 hours, and they continued to increase to $25.4 \pm 9.7$ and $3.5 \pm 1.0 \mu \mathrm{g} / \mu \mathrm{g}$ in the VE and dermis at 24 hours, respectively. The reason that Lamisil $^{\circledR}$ Once ${ }^{\mathrm{TM}}$ was applied for 24 hours is that it can reach MIC in the dermis at 24 hours, which could completely kill fungus in the dermis and then reduce the recurrence rate. To develop a formulation that is equivalent to or better than Lamisil $^{\circledR}$ Once ${ }^{\mathrm{TM}}$, the penetration of TB from various SLN formulations was evaluated to measure the amount of TB that penetrated into different skin layers. The results are summarized in Figure 5.

The first five formulations examined were divided into two groups: one group contained GMSa, CPa, and ATOc, which had the same surfactant/cosurfactant mixture, Cremophor RH40:PG of 4:1, but with different lipid phases. Concentrations in all skin layers were higher for the $\mathrm{CPa}$ formulation than those for the ATOc formulation, which is because the solubility of TB is higher in Compritol $^{\circledR} 888$ than that in Precirol ${ }^{\circledR}$ ATO5. Although TB has a higher solubility in GMS than Compritol $^{\circledR} 888$, particle sizes of the GMSa formulation increased to $>3000 \mathrm{~nm}$ (Figure 2), and were unable to penetrate the skin, so concentrations in the SC and dermis were the lowest. The second group contained ATOa, ATOb, and ATOc, which had the same lipid phase, Precirol ${ }^{\circledR}$ ATO5, with different surfactant/cosurfactant mixtures or ratios. No significant differences in permeation amounts were observed. It was concluded that utilizing a lipid phase in which TB is more soluble may enhance the loading content,
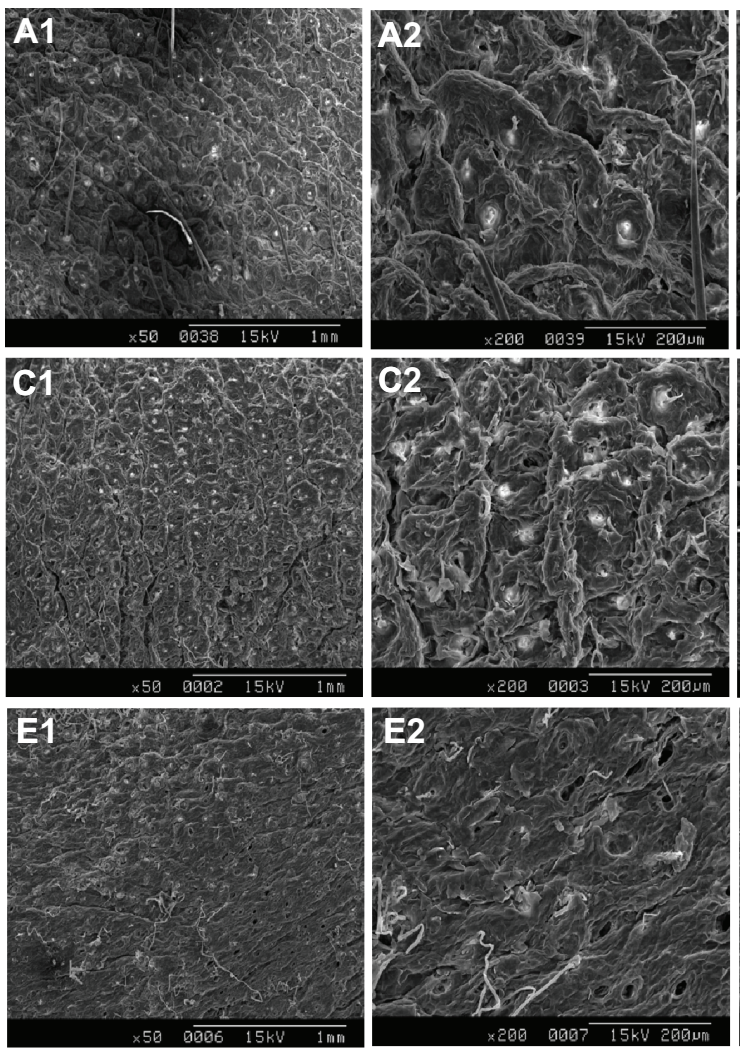
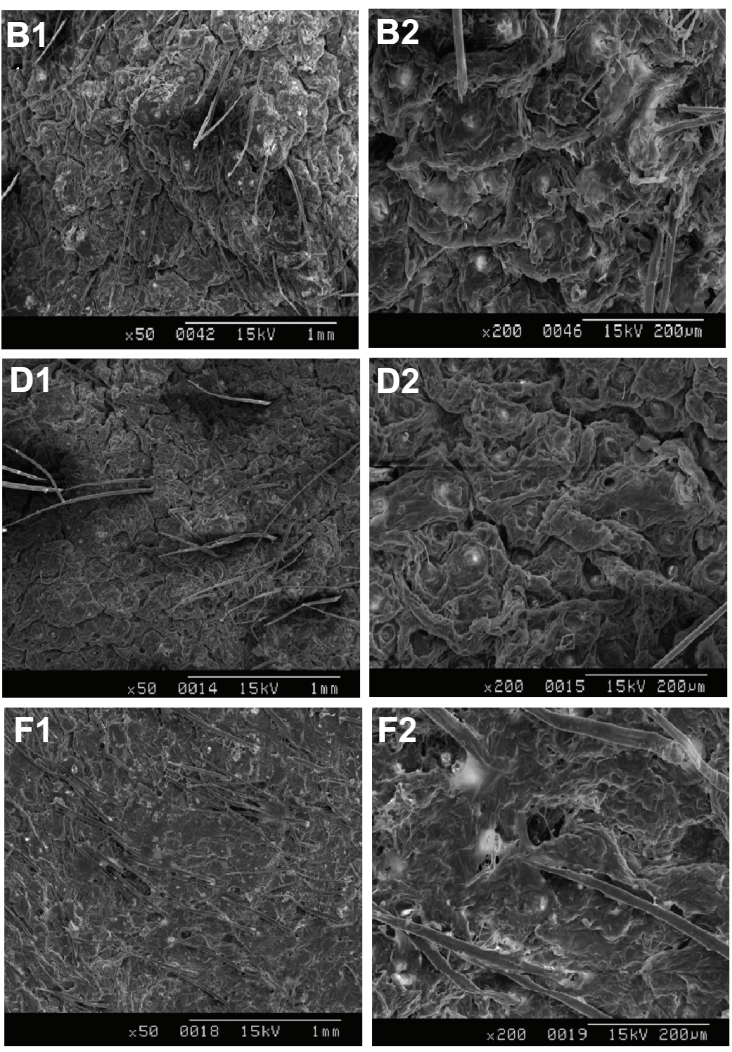

Figure 3 Scanning electron microscopy photography of the stratum corneum of nude mice that had been tape-stripped 0, I, 5, I0, I5, and 20 times, after in vitro transdermal penetration was magnified at 50× (AI, BI, CI, DI, EI, FI), respectively; and 200×(A2, B2, C2, D2, E2, F2), respectively. 


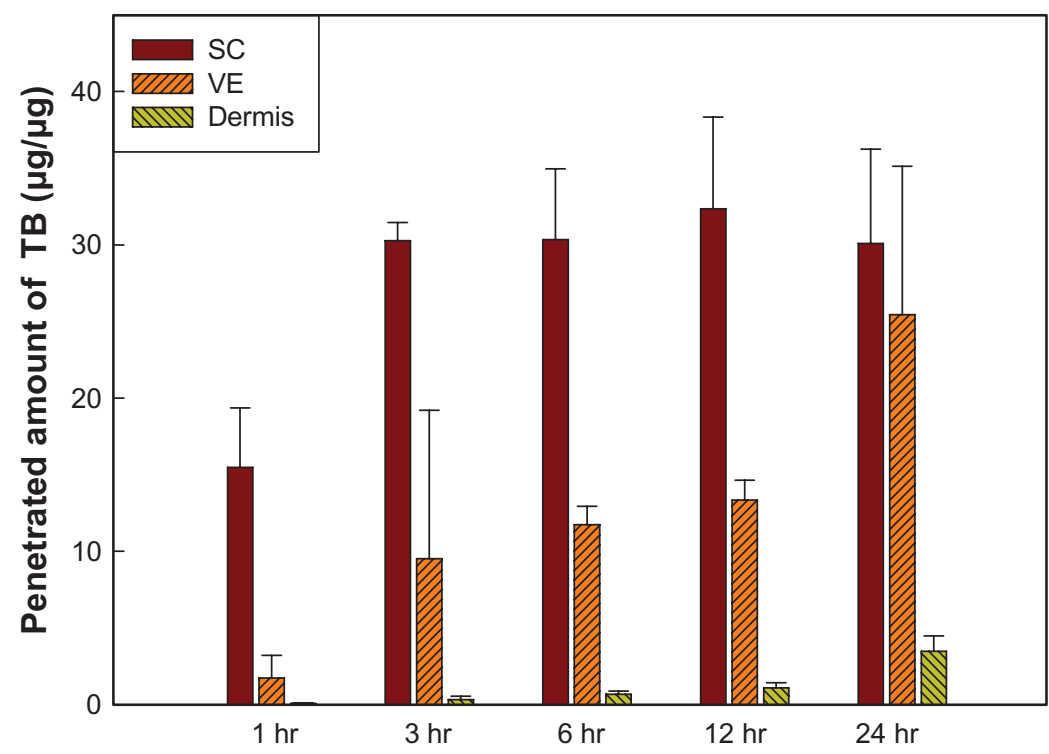

Figure 4 Amounts of terbinafine (TB) that penetrated into various skin layers at different time points after treatment with Lamisi ${ }^{\circledR}$ Once ${ }^{\mathrm{TM}}$. Abbreviations: SC, stratum corneum, VE, viable epidermis.

and a greater amount of TB can penetrate each skin layer, but changes in the surfactant system or ratio seemed to have limited effects.

To enhance the penetration of TB into the various skin layers, ethanol was added to the $\mathrm{CPaI}$ formulation (Table 1) because the evaporation of ethanol may result in a higher concentration of TB on the skin surface and increase the $C_{\mathrm{d}}$ factor in the denominator of the Noyes-Whitney equation to enhance penetration. The ratio of ethanol had to be $<5 \%$; otherwise, the formulations would be unstable and turbid.
However, the data showed that the amount that penetrated the various skin layers decreased. It was assumed that the addition of ethanol increased the solubility of TB in the water phase, which consequently decreased the loading content in the lipid phase and caused less TB to be available for penetration into the skin.

Etchants, such as citric acid and tartaric acid, were added to formulations $\mathrm{CPb} 10$ and $\mathrm{CPc} 10$ (Table 1) to delete the barrier effect of the SC and hopefully enhance the penetration ability of the drug. However, Figure 5 shows that lower

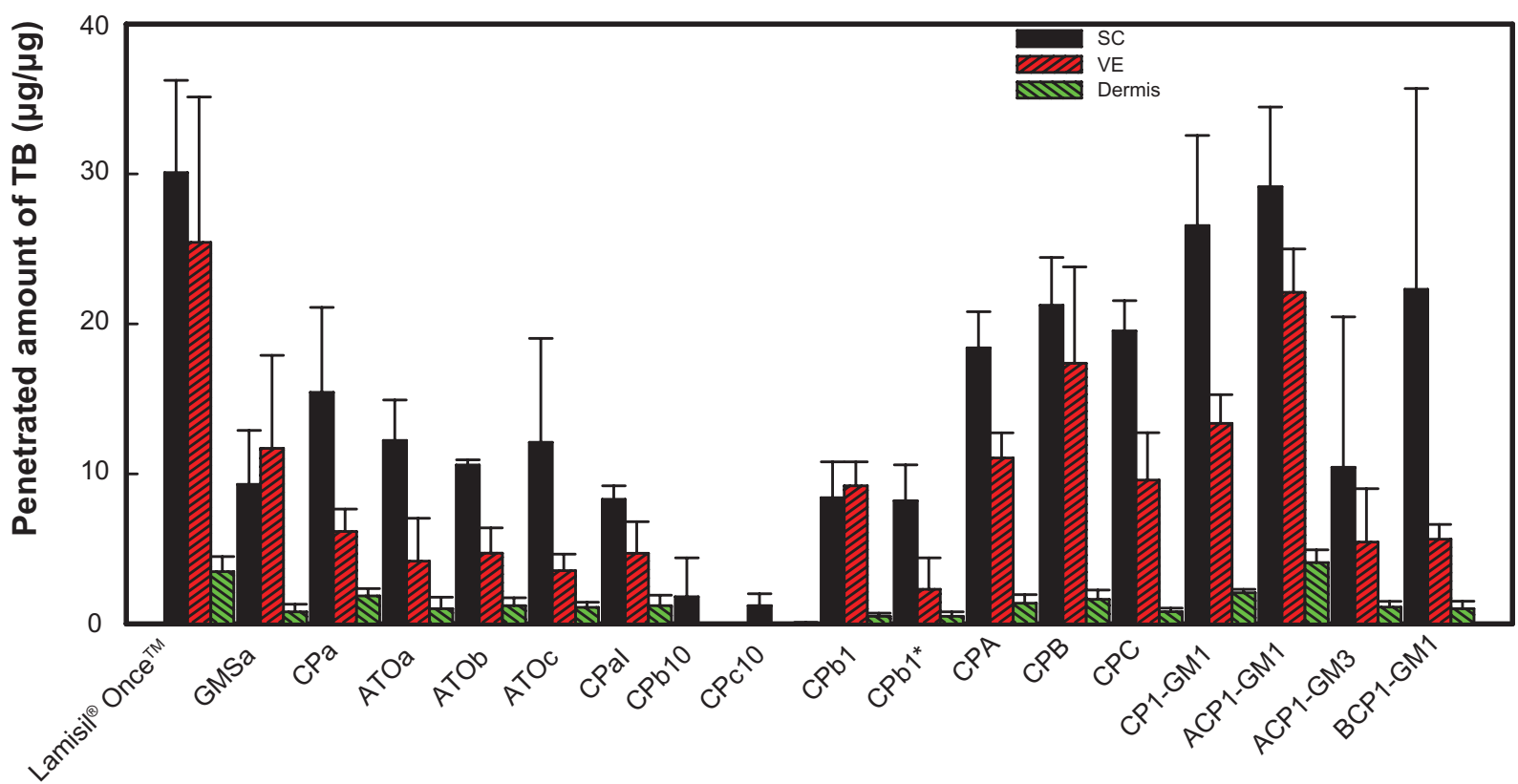

Figure 5 Amounts of terbinafine (TB) that penetrated into different skin layers after treatment with various solid lipid nanoparticle (SLN) formulations for 24 hours. Abbreviations: SC, stratum corneum; VE, viable epidermis; GMS, glyceryl monostearate; CP, Compritol ${ }^{\circledR} 888$; RH40, $^{2}$ remophor RH40; PG, I,2-propylene glycol. 
penetrated amounts of TB were still detected in the SC, and no TB was detected in the VE or dermis. It seems that the addition of etchants removed the SC and changed the structure of the skin, which may have altered the entry path of the drug into the skin and affected the partition coefficient $(K)$, thus reducing the amount of TB that penetrated the skin. Furthermore, even when the amount of etchant was reduced to $1 \%$ as in the $\mathrm{CPbI}$ formulation, the amount that penetrated each skin layer insignificantly increased. The possible reason is that the highest solubility of $\mathrm{TB}$ is at $\mathrm{pH} 3$, and the $\mathrm{pH}$ value of formulation $\mathrm{CPbI}$ was 2.7 , so some portion of the drug might have penetrated into the water phase instead of the lipid phase, thus decreasing the amount of TB available for penetration. This result does not seem to be consistent with that reported by Repka et $\mathrm{al}^{28}$ and Vaka et $\mathrm{al},{ }^{29}$ the former of which conducted in vitro permeability studies by applying ketoconazole to human nail samples treated with an etching agent (10\% phosphoric acid gel) and demonstrated a significant increase in drug permeability compared to a control (unetched nail samples).

By increasing the percent of the lipid phase as in formulations CPA and CPB (Table 1), the amounts of TB that penetrated into the SC and VE increased by 1.37 and 2.8 times, respectively (Figure 5), but there was only a slight change in the dermis. However, formulation CPC with a $6 \%$ lipid phase was out of the range of SLNs, as its particle size was as large as $1019.5 \pm 115.7 \mathrm{~nm}$ (Figure 2). Thus, the great increase in particle size seemed to hinder the drug from penetrating the skin.

Although the concentrations of TB in the skin layers were enhanced by increasing the ratio of the lipid phase under a limitation of $<5 \%$, the concentration of TB that penetrated each skin layer was still lower than that of Lamisil ${ }^{\circledR}$ Once $^{\mathrm{TM}}$. We further combined different lipid phases to increase the loading content, and the results are shown in Figure 5. TB was the most soluble in GMS, but SLNs formed using GMS as the lipid phase were too unstable to remain as nanoparticles, as shown above. Compritol ${ }^{\circledR} 888$ was combined with GMS in two ratios (1:1 and 1:3) with various percentages of the lipid phase $(3 \%-5 \%)$ as formulations CP1-GM1 (3\% lipid phase; 1:1), ACP1-GM1 (4\%; 1:1), ACP1-GM3 (4\%; 1:3), and BCP1-GM1 $(5 \% ; 1: 1)$. At the same ratio as Compritol ${ }^{\circledR}$ 888:GMS, amounts of TB that penetrated into all skin layers were the highest for ACP1-GM1. It was found that ACP1GM1 had the highest amount of TB to penetrate all skin layers, and the particle size remained quite stable. ACP1-GM3 containing a larger fraction of GMS was still unstable as was the SLN formulation using GMS as the sole lipid phase.
This is because its particle size increased to $>3000 \mathrm{~nm}$ within 1 day, leading to a decrease in drug penetration. A higher ratio of the lipid phase (5\%) in formulation BCP1GM1 did not enhance the penetration of TB into the skin for the same reason that increasing particle sizes hindered its penetration. It was concluded that the combination of lipid phases was able to increase the amount and stability of TB that penetrated into the various skin layers, simply because GMS increased the drug loading content and Compritol ${ }^{\circledR}$ 888 stabilized the SLNs.

Comparisons of the amounts of TB that penetrated from formulations examined with Lamisil ${ }^{\circledR}$ Once $^{\mathrm{TM}}$ at different time points into various skin layers are shown in Figure 6, which demonstrates that all formulations reached a steady state within 3 hours in the SC, and the amount that penetrated from formulations CP1-GM1 and ACP1-GM1 insignificantly resembled those of Lamisil ${ }^{\circledR}$ Once $^{\mathrm{TM}}$. However, only the amount of TB that penetrated into the VE from ACP1-GM1 was similar to Lamisil ${ }^{\circledR}$ Once $^{\mathrm{TM}}$. In the dermal layer, only the amount of TB that penetrated from ACP1-GM1 at any time point was significantly higher than that of Lamisil ${ }^{\circledR}$ Once $^{\mathrm{TM}}$ except at 3 and 24 hours. The amount of TB from ACP1GM1 that penetrated the dermis layer at 12 hours was much higher than that of Lamisil ${ }^{\circledR}$ Once $^{\mathrm{TM}}$, and it was almost the same as that from Lamisil ${ }^{\circledR}$ Once $^{\mathrm{TM}}$ at 24 hours. The fact that SLN formulations delivered more terbinafine into the dermis than Lamisil ${ }^{\circledR}$ Once ${ }^{\mathrm{TM}}$ did might be due to the ability to load more lipophilic drugs, its nanosize, and its occlusive effect. SLNs are good carriers for lipophilic molecules; moreover, the highly specific surface area of nanometer-sized SLN formulations facilitates the contact of drugs with SC enhanced terbinafine penetration. The increased amount of terbinafine in the dermis is also due to the occlusion properties. After applying SLN formulations to the skin surface, water evaporated and an adhesive layer occluding the skin surface was formed. The hydration of SC then increased, which facilitated drug penetration into deeper skin layers by decreasing corneocyte packing and widening the intercorneocyte gaps. ${ }^{23,24,30}$ Occlusive effects were well correlated to particle size; nanoparticles were 15-fold more occlusive than microparticles, and particles smaller than $400 \mathrm{~nm}$ were more favorable. ${ }^{31}$ Thus, ACP1-GM1 with particle size of $233.0 \mathrm{~nm}$ should have the ability to form an occlusive film on the surface of skin, increase the hydration of SC, and improve the permeation of terbinafine into skin. This indicated that the application of ACP1-GM1 for 12 hours might have an efficacy comparable to that of Lamisil ${ }^{\circledR}$ Once ${ }^{\mathrm{TM}}$ for 24 hours, which would resolve the practical problem of the long administration period of Lamisil ${ }^{\circledR}$ Once $^{\mathrm{TM}}$. 


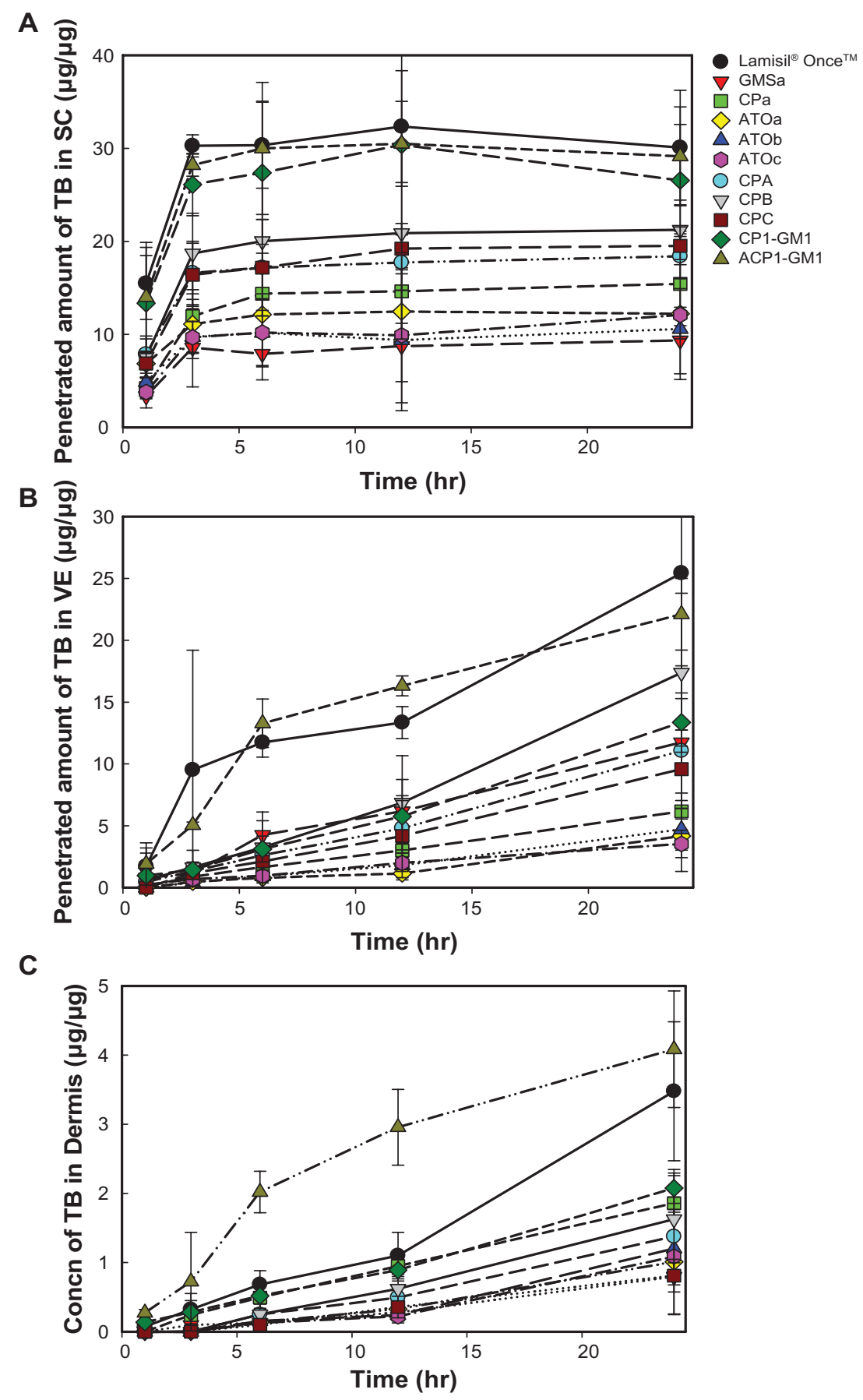

Figure 6 Amounts of terbinafine (TB) that penetrated into the stratum corneum (SC) (A), variable epidermis (VE) (B), and dermis (C) versus time profile after treatment with various solid lipid nanoparticle (SLN) formulations.

Abbreviations: GMS, glyceryl monostearate; Concn, concentrations; CP, Compritol ${ }^{\circledR}$ 888; RH40, Cremophor RH40; PG, I,2-propylene glycol.

\section{Conclusion}

The clinical efficacy of an antifungal agent depends on the concentration achieved in targeted skin tissues. This depends on several factors in the topical formulation, including the molecular mass and concentration of the drug that is administered, the duration of contact with the target tissues, and the ability of the compound to penetrate the tissues. Although frequent topical application is a useful means of achieving therapeutic levels, it is laborious. In this study, an optimized SLN formulation is presented as an alternative with improved permeability and decreased dosage frequency (hence improving compliance) and side effects. This optimized SLN for TB will improve the safety, cost, and tolerance of antifungal therapy. It was concluded that optimized SLN formulation of ACP1-GM1 applied for 12 hours might have efficacy comparable to that of Lamisi ${ }^{\circledR}$ Once $^{\mathrm{TM}}$ for 24 hours. 


\section{Disclosure}

The authors report no conflicts of interest in this work.

\section{References}

1. Pathan IB, Setty CM. Chemical penetration enhancers for transdermal drug delivery systems. Trop J Pharm Res. 2009;8(2):173-179.

2. Thiruganesh R, Uma Devi SK. Solid lipid nanoparticle and nanoparticle lipid carrier for controlled drug delivery - a review of state of art and recent advances. International Journal of Nanoparticles. 2010;3(1):32-52.

3. Sabadin CS, Benvegnú SA, Fontoura MMC, Saggin LMF, Tomimori J, Fischman O. Onychomycosis and tinea pedis in athletes from the State of Rio Grande Do Sul (Brazil): a cross-sectional study. Mycopathologia. 2010;171(3):183-189.

4. Krishnan-Natesan S. Terbinafine: a pharmacological and clinical review. Expert Opin Drug Deliv. 2009;10(16):2723-2733.

5. Alberti I, Kalia YN, Naik A, Bonny JD, Guy RH. In vivo assessment of enhanced topical delivery of terbinafine to human stratum corneum. J Control Release. 2001;71(3):319-327.

6. Kaur IP, Kakkar S. Topical delivery of antifungal agents. Expert Opin Drug Deliv. 2010;7(11):1303-1327.

7. Gupta AK, Chow M, Daniel CR, Aly R. Treatments of tinea pedis. Dermatol Clin. 2003;21(3):431-462.

8. Robert MEM, Kalia YN. New developments in topical antifungal therapy. Am J Drug Delivery. 2006;4(4):231-247.

9. Segal BH, Walsh TJ. Current approaches to diagnosis and treatment of invasive aspergillosis. Am J Respir Crit Care Med. 2006;173(7):707-717.

10. O'Brien TP. Therapy of ocular fungal infections. Ophthalmol Clin North Am. 1999;12(1):33-50.

11. Faergemann J, Zehender H, Denouel J, Millerioux L. Levels of terbinafine in plasma, stratum corneum, dermis-epidermis (without stratum corneum), sebum, hair and nails during and after $250 \mathrm{mg}$ terbinafine orally once per day for four weeks. Acta Derm Venereol. 1993;73(4):305-309.

12. Faergemann J, Zehender H, Jones T, Maibach I. Terbinafine levels in serum, stratum corneum, dermis-epidermis (without stratum corneum), hair, sebum and eccrine sweat. Acta Derm Venereol. 1991; 71(4):322-326.

13. Hill S, Thomas R, Smith SG, Finlay AY. An investigation of the pharmacokinetics of topical terbinafine $\left(\right.$ Lamisi $^{\mathbb{}}{ }^{\mathbb{}}$ ) 1\% cream. $\mathrm{Br} J$ Dermatol. 1992;127(4):396-400.

14. Hosseini-Yeganeh M, Andrew J, McLachlan. Tissue distribution of terbinafine in rats. $J$ Pharm Sci. 2001;90(11):1817-1828.

15. Hosseini-Yeganeh M, McLachlan AJ. Physiologically based pharmacokinetic model for terbinafine in rats and humans. Antimicrob Agents Chemother. 2002;46(7):2219-2228.
16. Alberti I, Kalia YN, Naik A, Guy RH. Assessment and prediction of the cutaneous bioavailability of topical terbinafine, in vivo, in man. Pharm Res. 2001;18(10):1472-1475.

17. Sch, Auml, Fer-Korting M, Schoellmann C, Korting HC. Fungicidal activity plus reservoir effect allows short treatment courses with terbinafine in tinea pedis. Skin Pharmacol Physiol. 2008;21(4):203-210.

18. Zur Mühlen A, Mehnert W. Drug release and release mechanism of prednisolone loaded solid lipid nanoparticles. Pharmazie. 1998;53(8):552-555.

19. Zur Mühlen A, Schwarz C, Mehnert W. Solid lipid nanoparticles (SLN) for controlled drug delivery - drug release and release mechanism. Eur J Pharm Biopharm. 1998;45(2):149-155.

20. Müller RH, Mäder K, Gohla S. Solid lipid nanoparticles (SLN) for controlled drug delivery - a review of the state of the art. Eur J Pharm Biopharm. 2000;50(1):161-177.

21. Wissing SA, Müller RH. The influence of solid lipid nanoparticles on skin hydration and viscoelasticity - in vivo study. Eur J Pharm Biopharm. 2003;56(1):67-72.

22. Jenning V, Gysler A, Schäfer-Korting M, Gohla SH. Vitamin A loaded solid lipid nanoparticles for topical use: occlusive properties and drug targeting to the upper skin. Eur J Pharm Biopharm. 2000; 49(3):211-218.

23. Lv Q, Yu A, Xi Y, et al. Development and evaluation of penciclovirloaded solid lipid nanoparticles for topical delivery. Int J Pharm. 2009;372(1-2):191-198.

24. Schäfer-Korting M, Mehnert W, Korting HC. Lipid nanoparticles for improved topical application of drugs for skin diseases. Adv Drug Delivery Rev. 2007;59(6):427-443.

25. Mandawgade SD, Patravale VB. Development of SLNs from natural lipids: application to topical delivery of tretinoin. Int J Pharm. 2008;363(1-2):132-138.

26. Castro GA, Coelho ALLR, Oliveira CA, Mahecha GAB, Oréfice RL, Ferreira LAM. Formation of ion pairing as an alternative to improve encapsulation and stability and to reduce skin irritation of retinoic acid loaded in solid lipid nanoparticles. Int J Pharm. 2009;381(1):77-83.

27. Sachdeva V, Siddoju S, Yu YY, Kim HD, Friden PM, Banga AK. Transdermal iontophoretic delivery of terbinafine hydrochloride: Quantitation of drug levels in stratum corneum and underlying skin. Int J Pharm. 2010;388(1-2):24-31.

28. Repka MA, Mididoddi PK, Stodghill SP. Influence of human nail etching for the assessment of topical onychomycosis therapies. Int $J$ Pharm. 2004;282(1-2):95-106.

29. Vaka SRK, Murthy SN, O'Haver JH, Repka MA. A platform for predicting and enhancing model drug delivery across the human nail plate. Drug Dev Ind Pharm. 2011;37(1):72-79.

30. Cevc G. Lipid vesicles and other colloids as drug carriers on the skin. Adv Drug Delivery Rev. 2004;56(5):675-711.

31. Wissing SA, Müller RH. Solid lipid nanoparticles (SLN): a novel carrier for UV blockers. Pharmazie. 2001;56(10):783-786.
International Journal of Nanomedicine

\section{Publish your work in this journal}

The International Journal of Nanomedicine is an international, peerreviewed journal focusing on the application of nanotechnology in diagnostics, therapeutics, and drug delivery systems throughout the biomedical field. This journal is indexed on PubMed Central, MedLine, CAS, SciSearch ${ }^{\circledR}$, Current Contents ${ }^{\circledR} /$ Clinical Medicine,

\section{Dovepress}

Journal Citation Reports/Science Edition, EMBase, Scopus and the Elsevier Bibliographic databases. The manuscript management system is completely online and includes a very quick and fair peer-review system, which is all easy to use. Visit http://www.dovepress.com/ testimonials.php to read real quotes from published authors. 